\title{
Comparison of the Effect of Two Teach-Back Training and Pictorial Training Methods on Medication Adherence in Heart Failure Patients
}

\author{
Maryam Aghamohammadi', Mahnaz Khatiban², Alireza Soltanian ${ }^{3}$, Zahra Khalili4*
}

1. MSc, Student Research Center, School of Nursing and Midwifery, Hamadan University of Medical Sciences, Hamadan, Iran

2. Professor, Mother \& Child Care Research Center, Department of Medical-Surgical Nursing, School of Nursing and Midwifery, Hamadan University of Medical Sciences, Hamadan, Iran

3. Professor, Department of Statistics, Faculty of Health, Hamadan University of Medical Sciences, Hamadan, Iran

4. Faculty Member, Research Center for Chronic Disease Care, Department of Medical Surgical Nursing, Faculty of Nursing and Midwifery, Hamadan University of Medical Sciences, Hamadan, Iran

\section{Article Info}

Received: 2020/02/04;

Accepted: 2020/04/13;

Published Online: 2020/08/22

10.30699/ajnmc.28.3.193

Original Article

Use your device to scan and read the article online

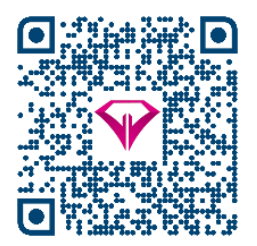

\section{ABSTRACT}

Introduction: Medicinal nonadherence prevents the achievement of therapeutic goals in cardiovascular patients. Training is essential to increase medicinal adherence. Therefore, the present study compared the effect of two teach-back and pictorial training methods on the medication adherence in heart failure patients.

Methods: This quasi-experimental study was performed on 210 heart failure patients in Hamadan Heart Hospital in 2019. Patients were selected by convenience sampling and randomly assigned to one of three groups of Teach-back, pictorial, and control training. Training sessions were held in three sessions on three consecutive days. Data were collected using demographic and medication adherence questionnaire (MMAS-8) before, immediately and 6 weeks after training. ANOVA, ANCOVA and Repeated measures ANOVA statistical tests were used.

Results: There was no statistically significant difference between the three groups in medicinal adherence at baseline. Immediately after training, medication adherence was significantly higher in teach-back and pictorial groups than the control group $(P<0.001)$, but there was no difference between teach back group and the pictorial group $(P=0.123)$. Six weeks after training, medicinal adherence was significantly higher in teach-back group compared to the control and pictorial group $(P<0.001)$. There was no significant difference between the two methods at different levels of education $(P>0.05)$.

Conclusion: Teach-back training helps maintain medicinal adherence in heart failure patients. Therefore, it is recommended that nurses use this training method to improve medicinal adherence in these patients.

Keywords: Heart Failure, Medication Adherence, Education

\section{Corresponding Information: \\ Zahra Khalili, Faculty Member, Research Center for Chronic Disease Care, Department of Medical Surgical Nursing, Faculty of Nursing and Midwifery, Hamadan University of Medical Sciences, \\ Hamadan, Iran. Email: zkhalili90@yahoo.com}

Copyright (C) 2020, This is an original open-access article distributed under the terms of the Creative Commons Attribution-noncommercial 4.0 International License which permits copy and redistribution of the material just in noncommercial usages with proper citation.

How to Cite This Article:

Aghamohammadi M, Khatiban M, Soltanian A, Khalili Z. Comparison of the Effect of Two TeachBack Training and Pictorial Training Methods on Medication Adherence in Heart Failure Patients. Avicenna J Nurs Midwifery care. 2020; 28 (3) : 
مقايسة تأثير دو روش آموزش تصويرى و آموزش بازخوردمحور بر ميزان تبعيت دارويى بيماران نارسايى قلبى

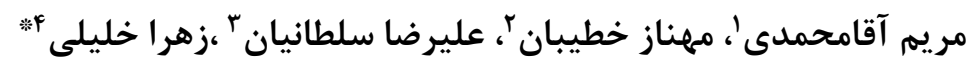

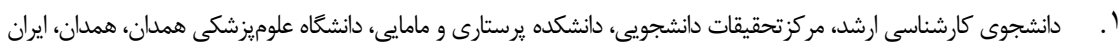

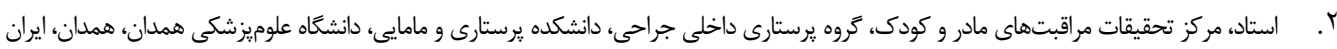

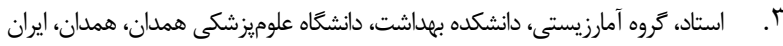

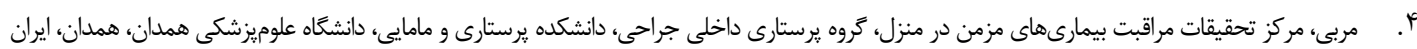

\begin{tabular}{|c|c|}
\hline 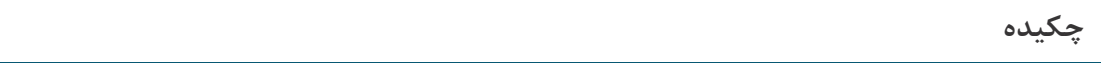 & اطلاعات مقاله \\
\hline 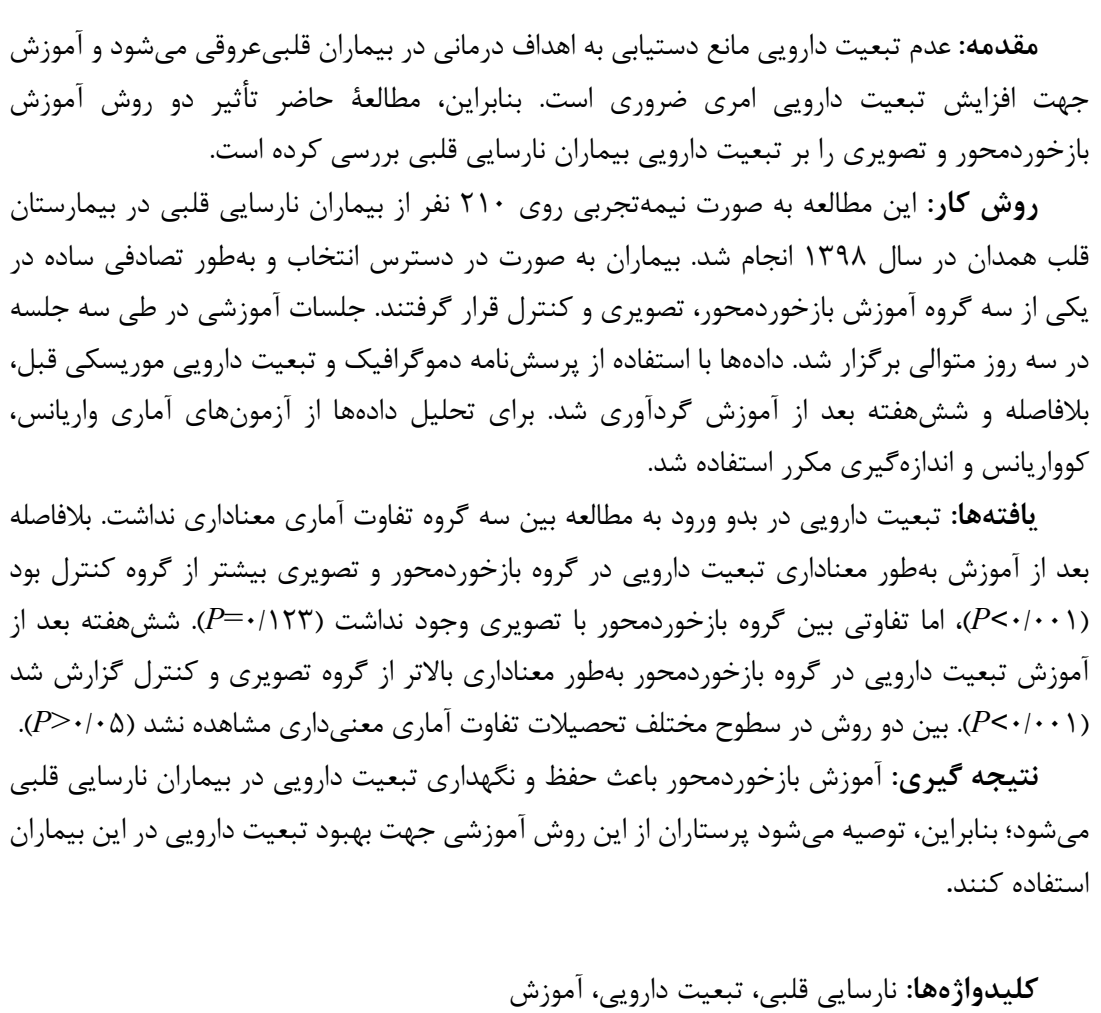 & 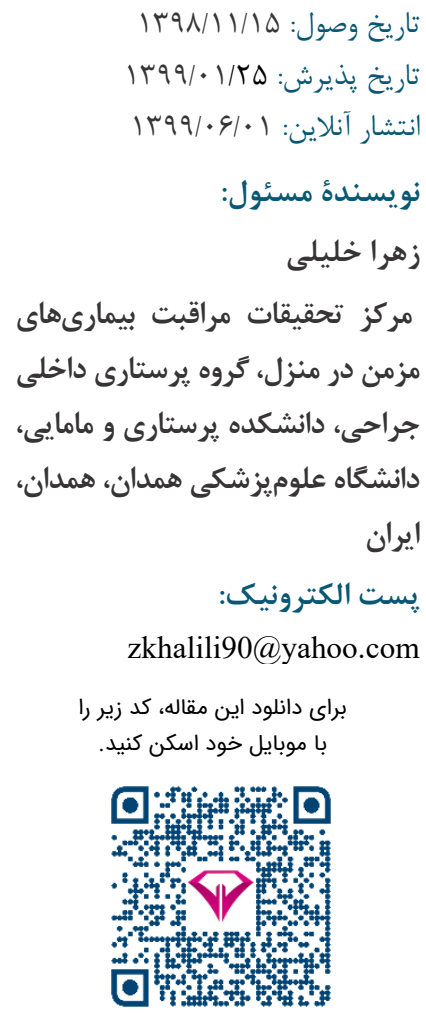 \\
\hline
\end{tabular}

بلهور معمول بهعنوان مصرف كمتر از • 1 درصد از دوزهاى

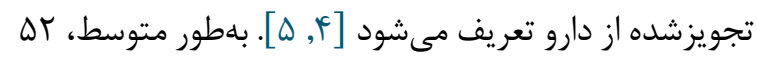

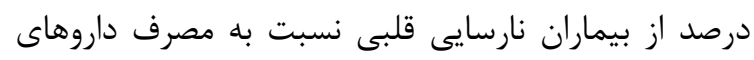

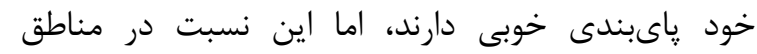

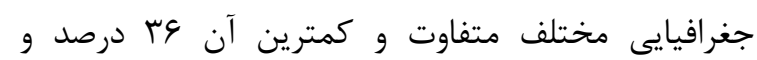

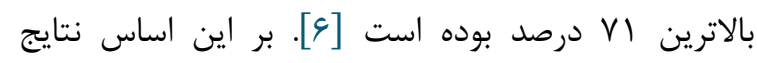

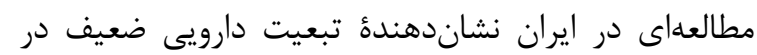
سالمندان مبتلا به بيمارىهاى مزمن بوده است و درى ندان

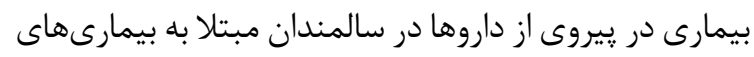

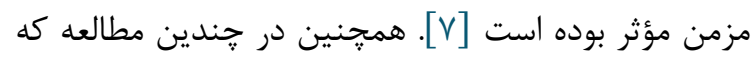

بيمارىهاى قلبى عروقى علت اول مرك در سراسر جهان

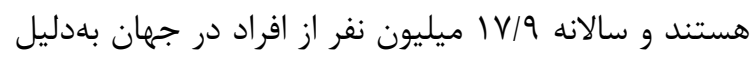

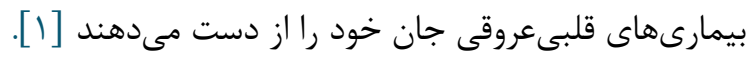
درمان بهعنوان بيشگيرى ثانويه در بيماران مبتلا به بيمارى

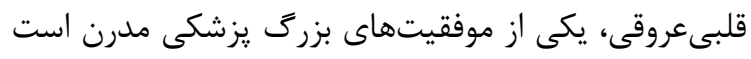

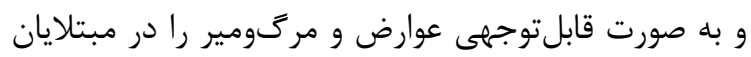

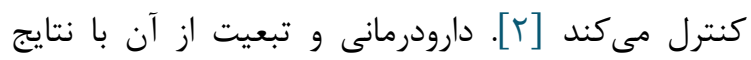

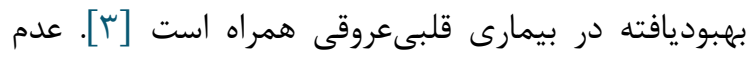
مصرف همأ دوزهاى دارو دقيقاً مطابق تجويز توسط بيمار دئران،

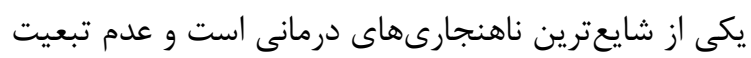


محتواى آموزشى به بيمار به صورت جهرهبهجهره آموزش

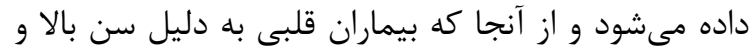

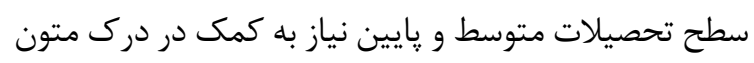

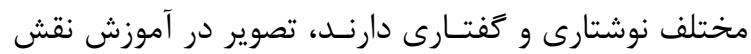

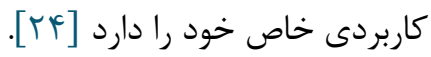

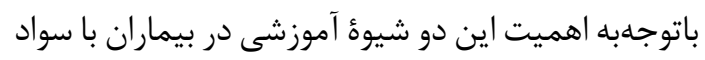

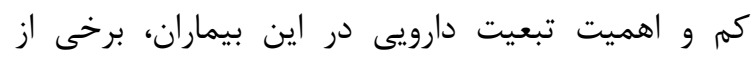

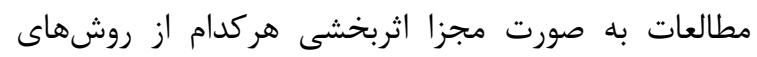

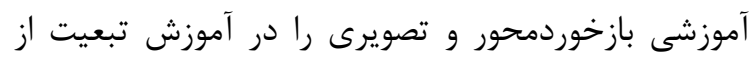

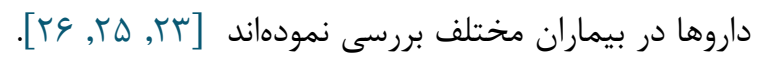
Negarandeh

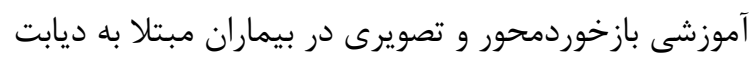

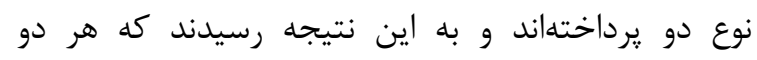
استراترى آموزشى بازخوردمحور و تصويرى ميىتوانند بهطور

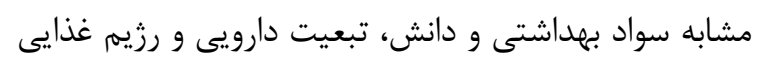

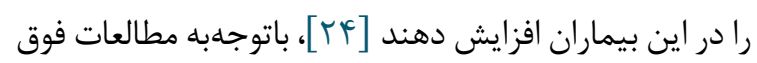

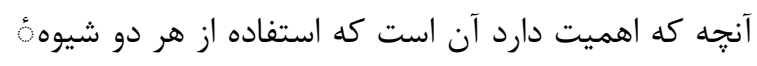

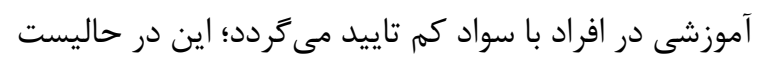

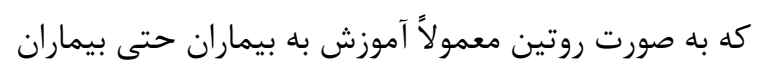

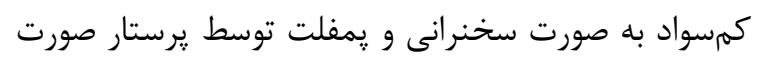

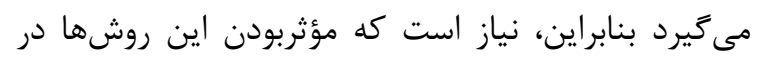

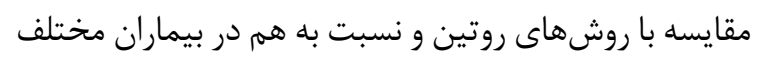

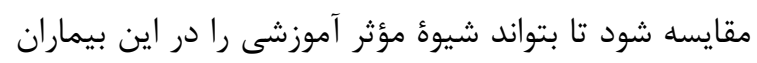

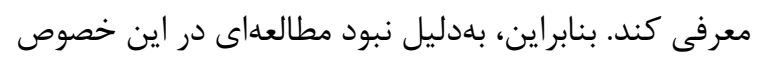

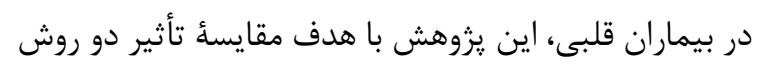

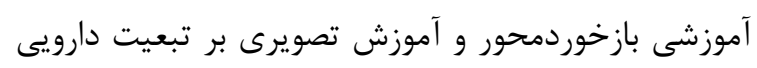
بيماران نارسايى قلبى انجام شد.

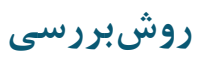

اين مطالعه به صورت نيمه تجربى با طرح سه كروهى

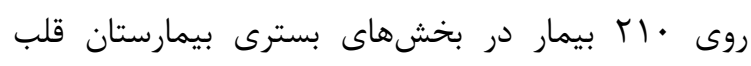

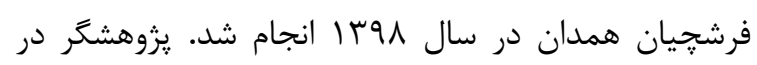

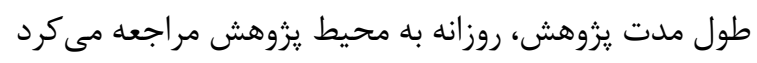

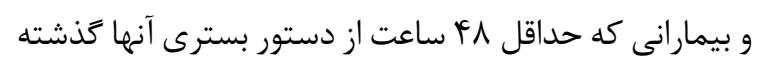

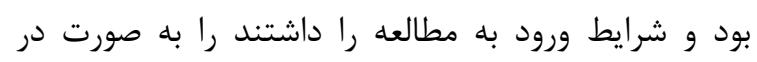

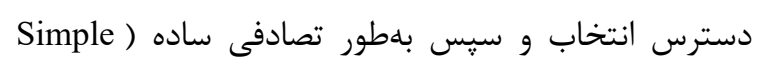

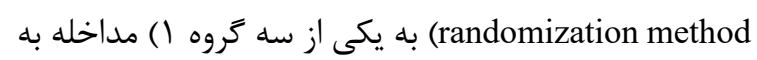

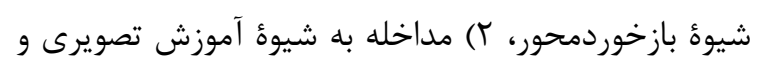

در نقاط مختلف ايران انجام شده است تبعيت دارويى در

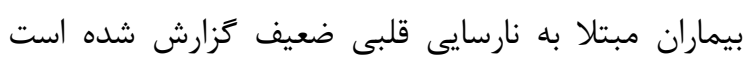

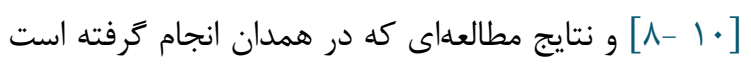

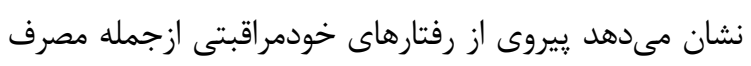

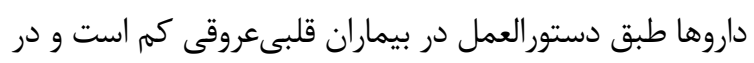

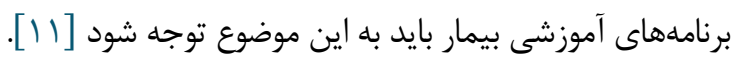

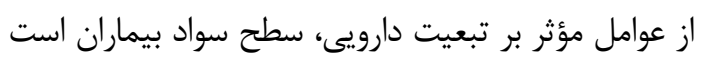

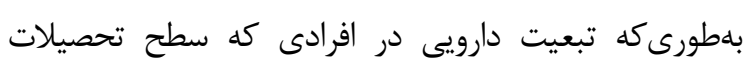
بالاترى دارند بهتر است [1 1 1]. بسيارى از مطالعات نشان دادهاند

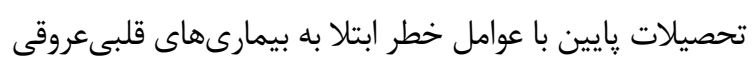

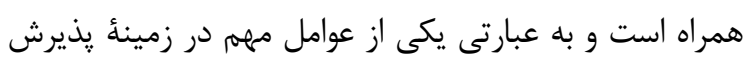

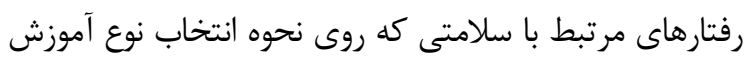

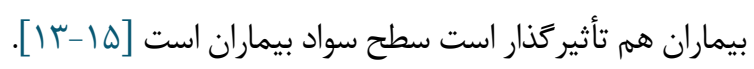
همجنين عدم تبعيت دارويى در سالمندان بيشتر است و واين

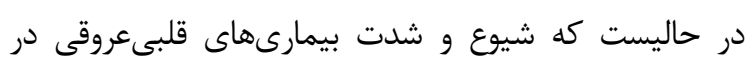

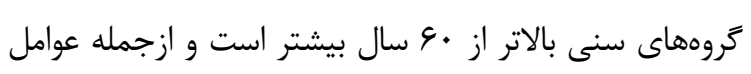

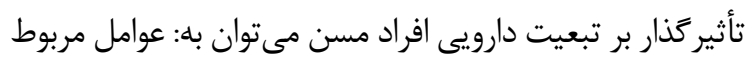

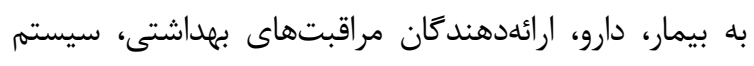

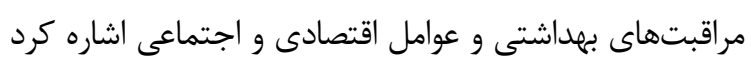

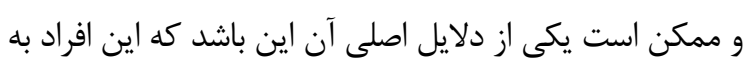

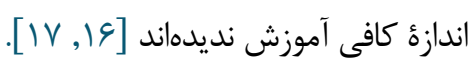

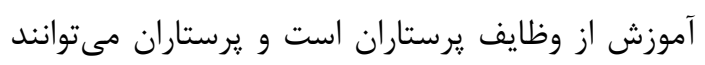
نقش مؤثرى روى انعطاف يذيرى بيماران مبتلا به نارسايى آني

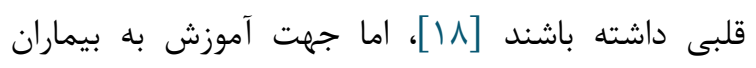

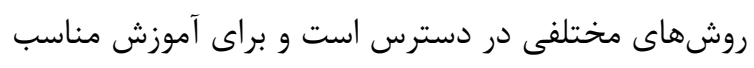

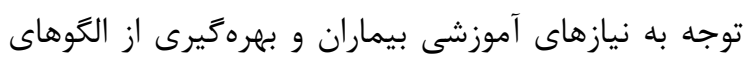

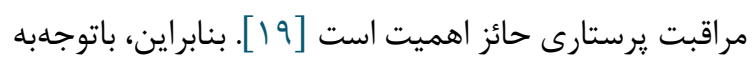

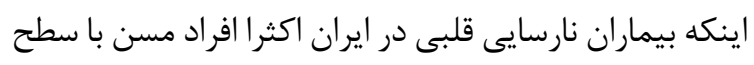

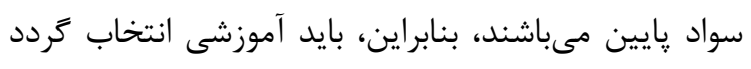

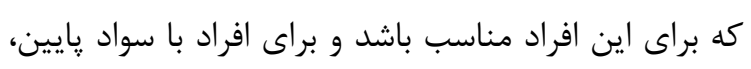

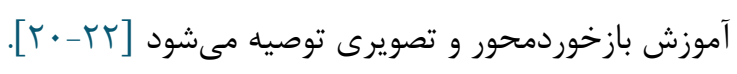

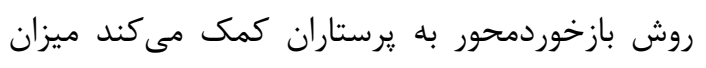

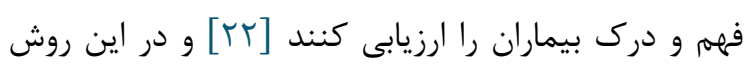

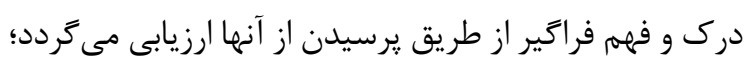

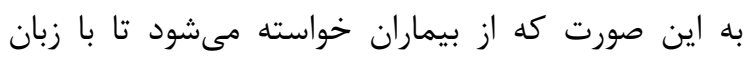

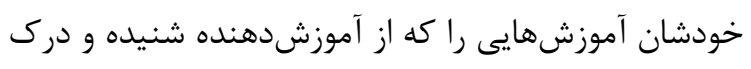

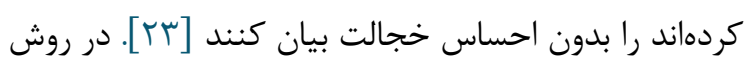

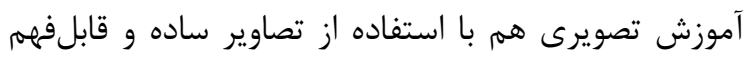


در اين يروهش براى آموزش بيماران ابتدا محتواى

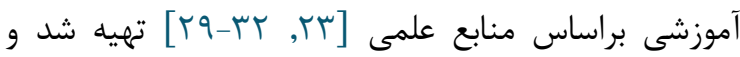

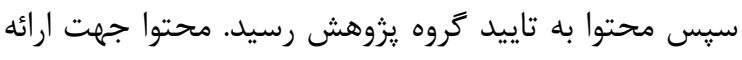

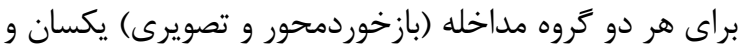

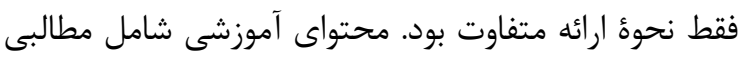

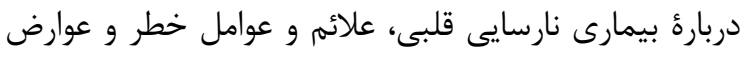

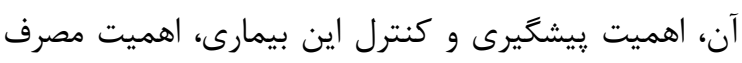

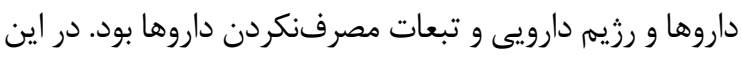
مطالعه هر سه تروه بازخوردمحور، تصويرى، و و كنترل

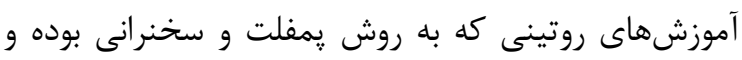

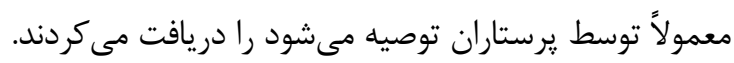

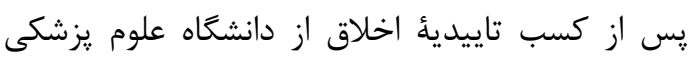
همدان و كسب مجوزهاى رسمى از بيمارستان مربوطه،

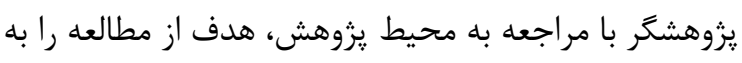

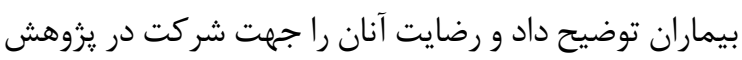
جلب كرد. به افراد اطمينان داده شد كه اطلاعات آنها در در دران

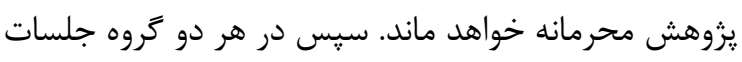

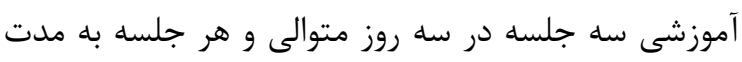

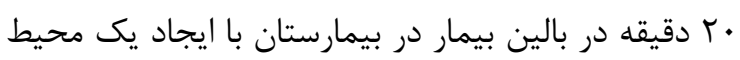

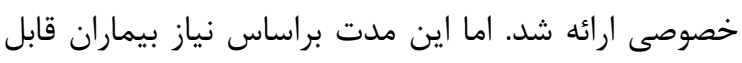

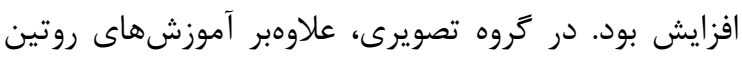

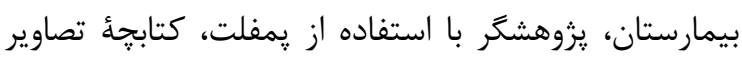

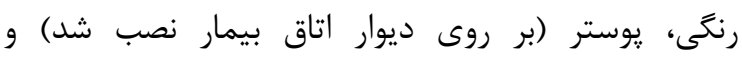

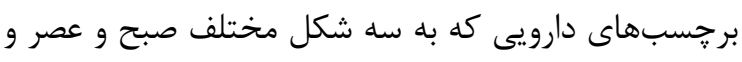

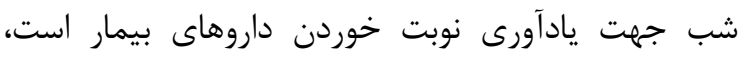

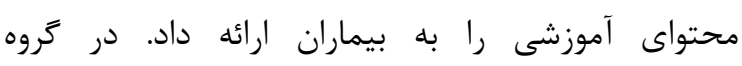

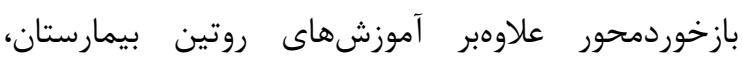

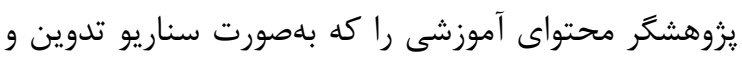

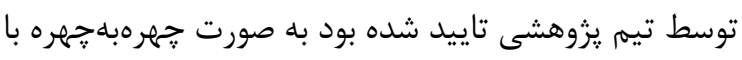

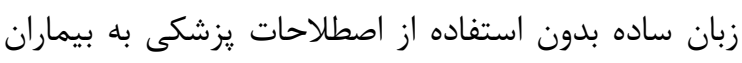

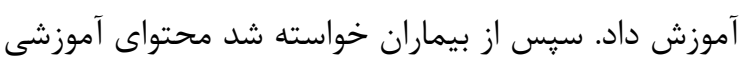

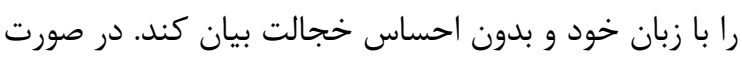
عدم درك صحيح مطالب توسط بيمار، مجددا محتواى خدان

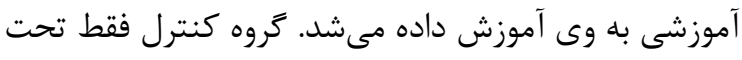

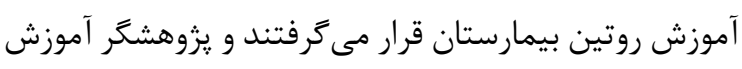
خاصى را به اين گروه ارائه نمى داد

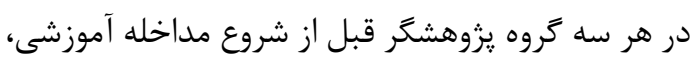

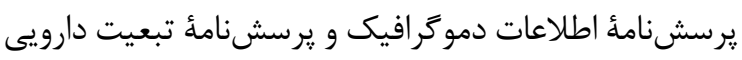

") گروه كنترل تخصيص مىداد. نمونه گيرى به اين روش تا

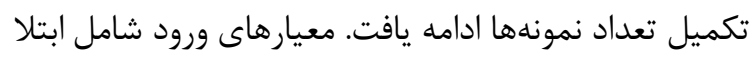

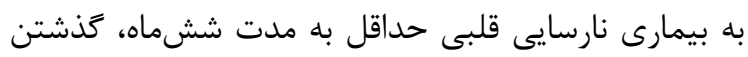

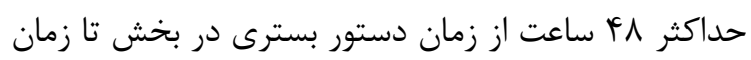

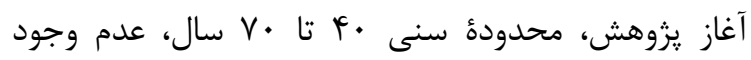

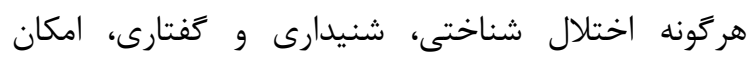

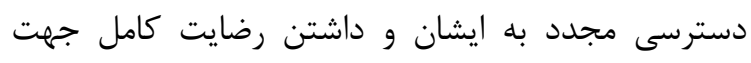

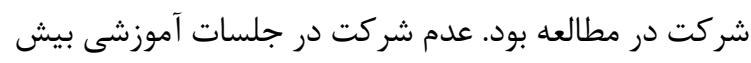

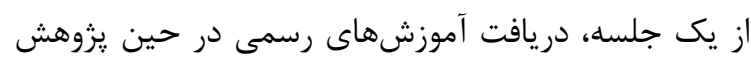

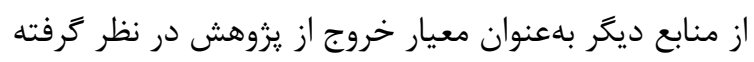

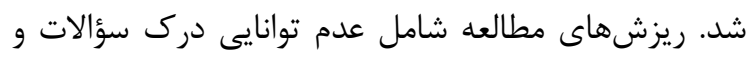

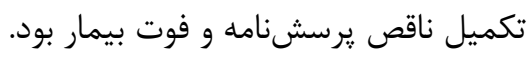

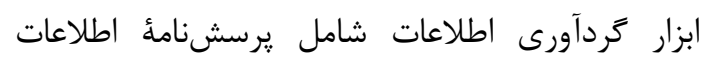

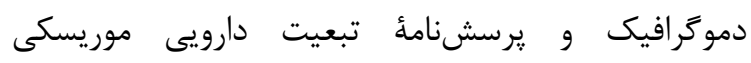
((MMAS-8) Morisky Medication Adherence Scale-8) بود. اين :رسشنامه براساس يرسشنامٔ تبعيت دارويى

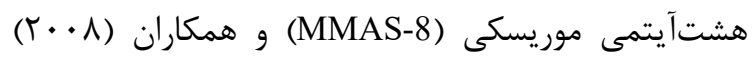

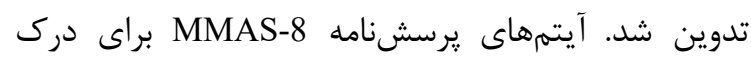

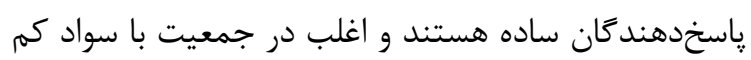

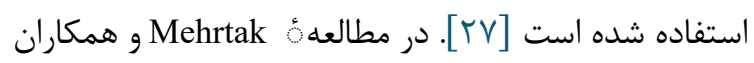

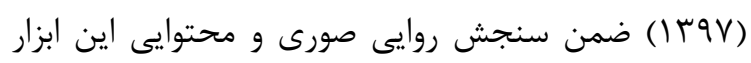

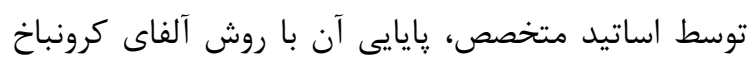

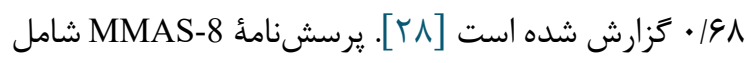

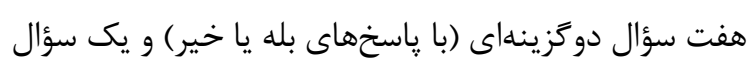

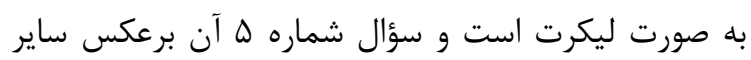

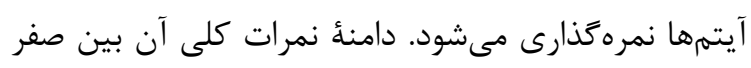

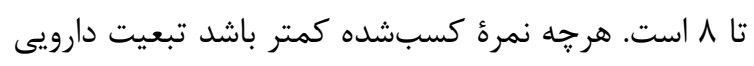

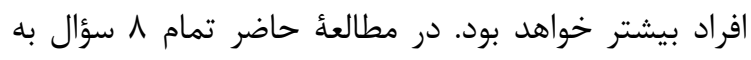

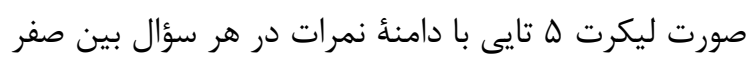

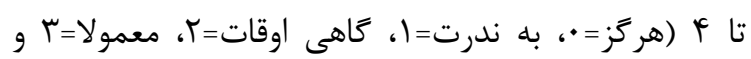

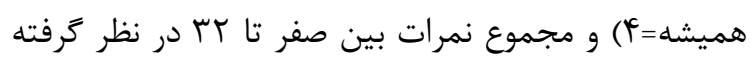

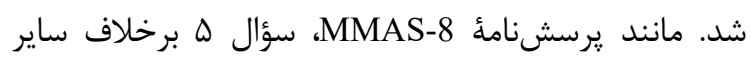

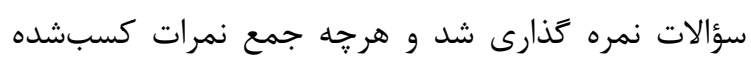

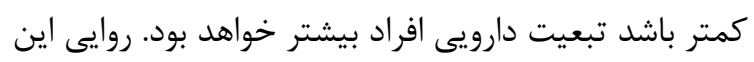

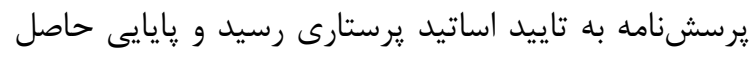

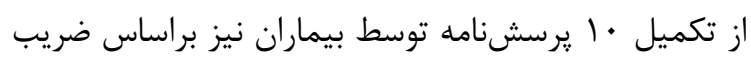

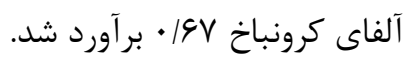


مريم آقامحمدى و همكاران $19 V$

انجام شد و سطح (SPSS Inc., Chicago, Ill., USA) معنىدارى كمتر از ه • • در نظر گرفته شد.

\section{بافته ها}

نتايج نشان داد تفاوت آمارى معنادارى بين سه گروه

موردبررسى ازنظر ميانگين سن، BMI) Body Mass Index)، فشارخون سيستوليك و دياستوليك و تعداد روزهاى بسترى در درئر بدو ورود به مطالعه براساس آزمون ANOVA وجود ندارد

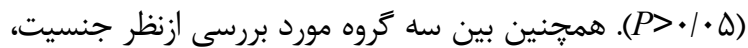

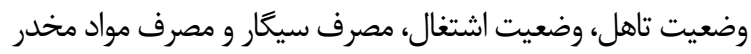
براساس نتايج آزمون كاى دو (X2) تفاوت آمارى معنى دارى وجوديت نداشته است (ه •/P> (P>). اين در حاليست كه بيشتر بيماران تحت مطالعه تحصيلات ابتدايى داشتند و بين سه كروه موردبررسى ازنظر

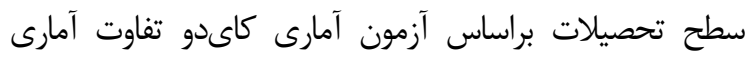

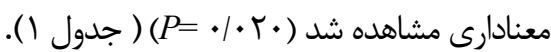
در بدو ورود به مطالعه بين سه گروه موردبررسى ازلحاظ

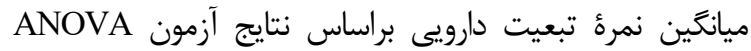

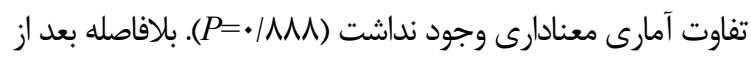
آموزش با تعديل اثر تحصيلات بين تبعيت دارويى سه گروه بازخوردمحور (Y/F

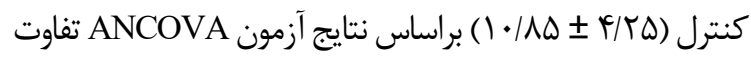

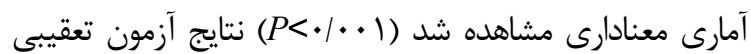

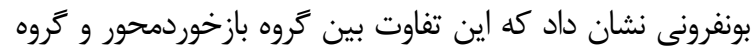

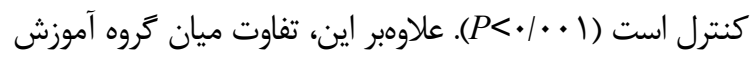

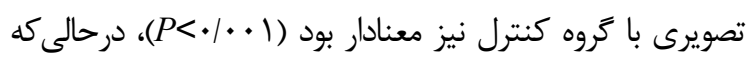

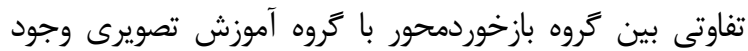

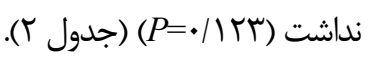

را با يرسش از بيماران و مندرجات موجود در يرونده تكميل

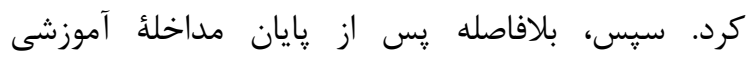

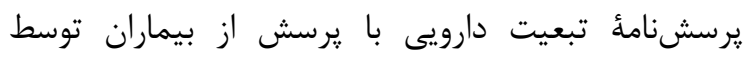

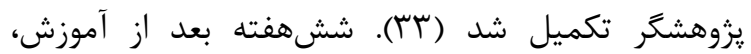
يزوهشگر ازطريق تماس تلفنى با بيماران، زمانى را جهت

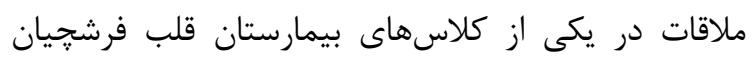

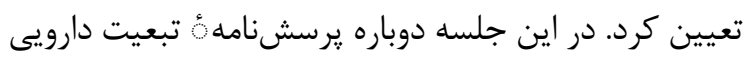

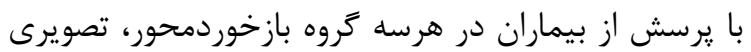
و كنترل تكميل شد.

بامنظور توصيف و مقايسُٔ دادههاى كيفى و كمى بين سه گروه قبل از شروع مداخله به ترتيب از آزمون آمارى لوصى

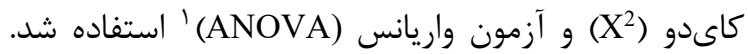

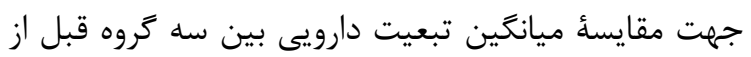

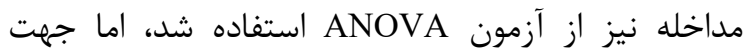
مقايسُٔ ميانگين تبعيت دارويى بين سه گروه در هر يك از از

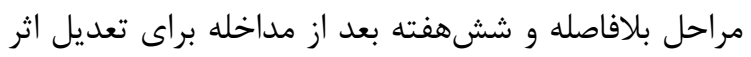

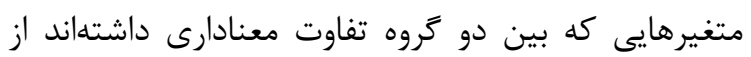
آزمون كوواريانس(ANCOVA) استفاده شد. باتوجهبه اينكه تبعيت دارويى در سه زمان (بدو ورود به مطالعه،

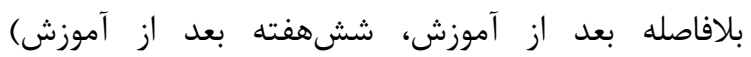

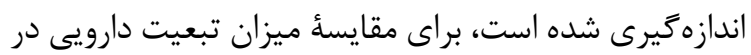
هر يك از گروهها در سه نوبت و همجنين مقايسه ميزان

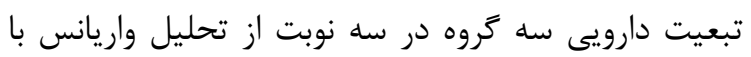
اندازمخيرىهاى مكرر (Repeated measures Anova) استفاده شد. همجنين از تست تعقيبى بونفرونى براى كشف آنس

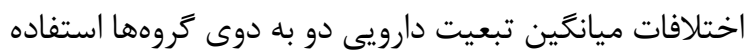

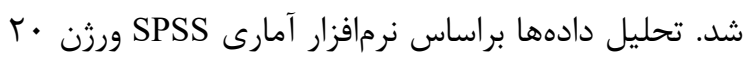

جدول ا. مقايسه مشخصات دمو

\begin{tabular}{|c|c|c|c|c|}
\hline \multirow[b]{2}{*}{$\boldsymbol{P}$} & \multicolumn{3}{|c|}{ كَروههاى مورد بررسى } & \multirow[b]{2}{*}{ متغير ها } \\
\hline & 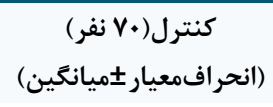 & 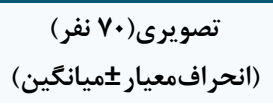 & 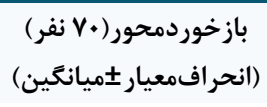 & \\
\hline a./IrF & $\Delta \Lambda / \Lambda \cdot \pm \mid r / \cdot \varphi$ & $g r / l f \pm\|\| / \Delta \Lambda$ & $\Delta N \wedge V \pm N D T$ & سن (سال) \\
\hline$a^{a} / Q F V$ & $r \varepsilon / r \cdot \pm r / \Delta r$ & $r V \pm F / Q V$ & $r \varepsilon / 4 \Delta \pm r / \varepsilon \Delta$ & $(\mathrm{kg} / \mathrm{m} 2) \mathrm{BMI}$ \\
\hline $\mathrm{a} \cdot / \cdot \Delta q$ & $\mid r r / D \cdot \pm I V / \varepsilon \Lambda$ & $|r G / 9| \pm \mid V / G \wedge$ & $|r q / r| \pm \mid N / r r$ & $\begin{array}{c}\text { فشارخون سيستوليك } \\
\text { (mmHg) }\end{array}$ \\
\hline${ }^{a} \cdot / V T r$ & $\Lambda \cdot / 1 \Delta \pm \mid r / q T$ & $\Lambda I / \Delta \Lambda \pm I V / \& \Lambda$ & $\Lambda \cdot / r \Delta \pm I N / T r T$ & $\begin{array}{c}\text { فشارخون دياستوليك } \\
\text { (mmHg) }\end{array}$ \\
\hline
\end{tabular}

${ }^{2}$ Analysis of covariance (ANCOVA)

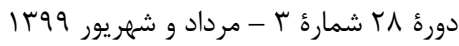

${ }^{1}$ Analysis of variance (ANOVA)

مجله مراقبت يرستارى و مامايى ابنسينا 
مريم آقامحمدى و همكاران 199

معنى دارى مشاهده شد ( ( • • •>

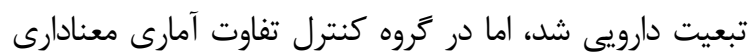

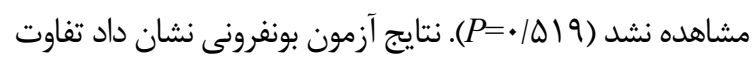
آمارى در بين تمام مراحل در گروه بازخوردمحور معنادار بوده

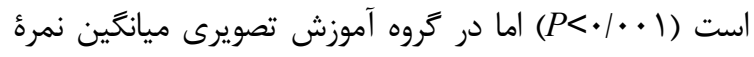

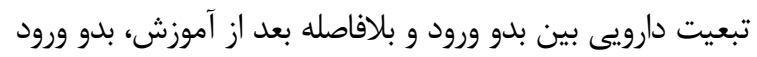

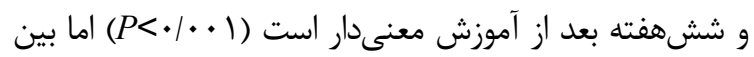

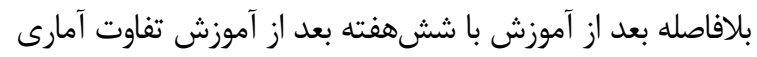

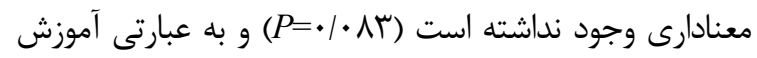

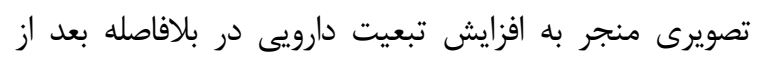

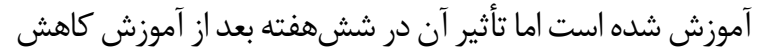

$$
\text { يافته است (شكل (1). }
$$

در مرحلة ششهفته بعد از آموزش نيز با تعديل اثر تحصيلات

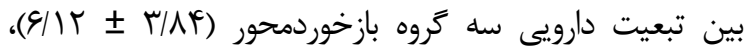
تصويرى (Y) نتايج آزمون ANCOVA تفاوت آمارى معنادارى وجود داشت

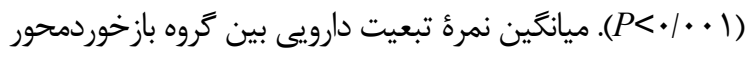

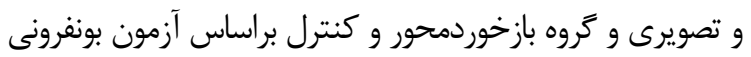

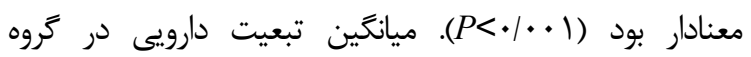
بازخوردمحور به صورت معنادارى بالاتر از گروه تصويرى و كنترل

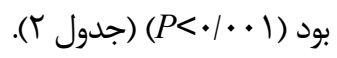
بين ميانگين نمره تبعيت دارويى در سه مرحله

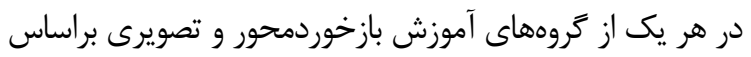

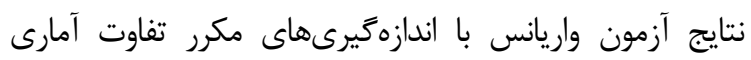

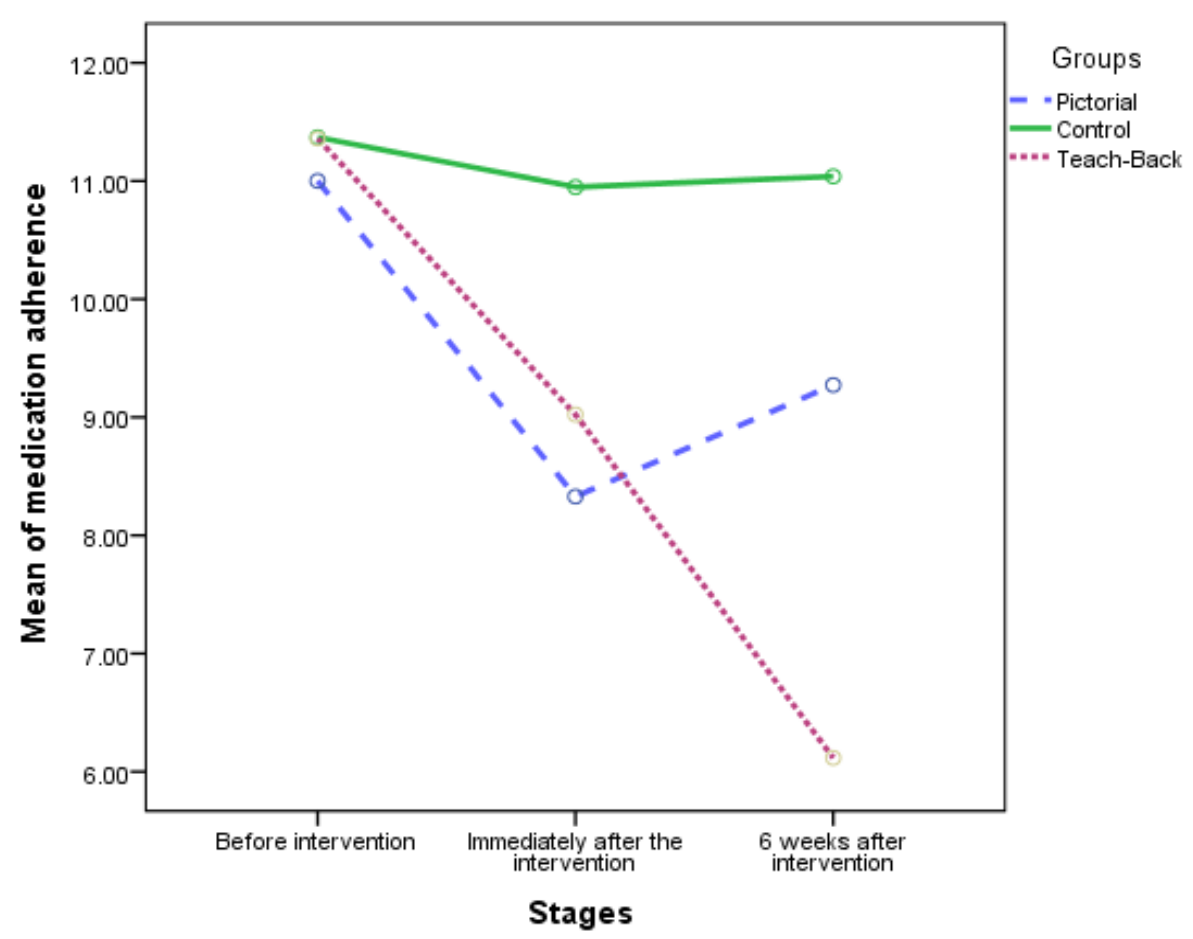

شكل ا. مقايسة ميانگين تبعيت دارويى بيماران در سه گروه كنترل، تصويرى و بازخوردمحور

بين سه گروه در بين مراحل بلافاصله با بدو ورود به مطالعه معنادار

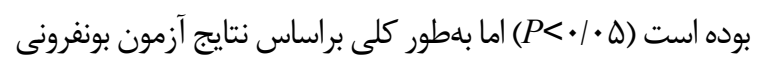

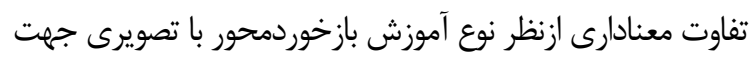

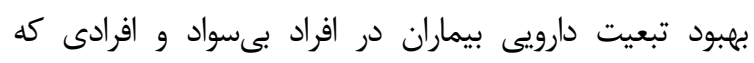
تحصيلات ابتدايى، راهنمايى، متوسطه و دييلم داشتهاند مشاهده

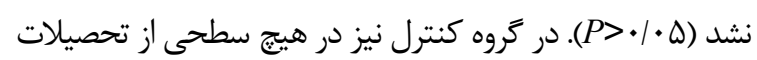

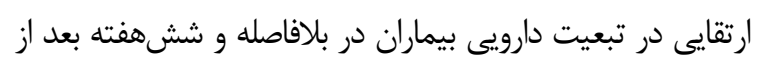

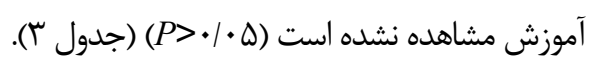

براساس سطح تحصيلات، تبعيت دارويى بين سه گروه در سه

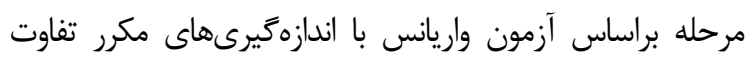

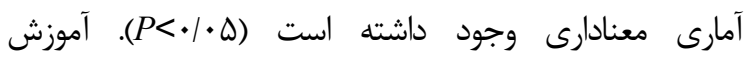
بازخوردمحور و تصويرى در افراد بىسواد و در افراد با تحصيلات ابتدايى، راهنمايى و متوسطه براساس آزمون تعقيبى بونفرونى به به به صورت معنادارى منجر به بهبود تبعيت دارويى بيماران در مرحلئ

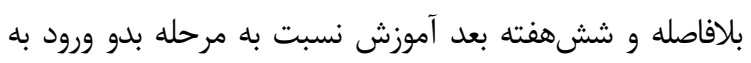

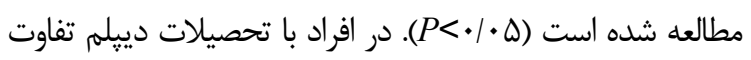




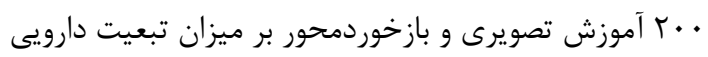

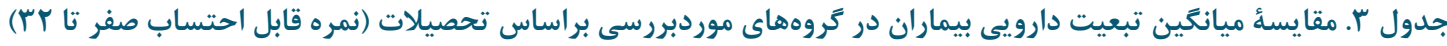

\begin{tabular}{|c|c|c|c|c|c|c|}
\hline 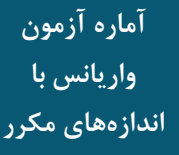 & شش هفته بعد از آموزش & بلافاصله بعد از آموزشي & انحر افمعيار دميانكين & $\begin{array}{l}\text { فراوانى } \\
\text { (درصد) }\end{array}$ & تروهها & تحصيلات \\
\hline$F=r / r)$ & G/Ar $\pm 1 / \Delta$. & $9 / \Delta \cdot \pm r$ & $1 r \pm r / 19$ & $9(\Lambda / 9)$ & بازخور دمحور & \multirow{3}{*}{ بىسواد } \\
\hline$d f=r$ & $N / I F \pm 1 / \% q$ & $V / V I \pm 1 / \wedge \Delta$ & $11 / F r \pm r / \cdot r$ & $V(1 \cdot)$ & تصويرى & \\
\hline$P=\cdot / \cdot r$. & $\| \pm 1 / 94$ & $1 \cdot / r \cdot \pm r / 19$ & $\mid r / \varphi \cdot \pm r / F \cdot$ & $\Delta(V / l)$ & كنترل & \\
\hline$F=\mid \Delta / \mu$. & $\Delta / \Delta q \pm \cdot / 4 q$ & $\Lambda / \Lambda r \pm \cdot / \Delta \Lambda$ & $11 / 11 \pm \cdot 109$ & $\operatorname{cr}(\varepsilon \cdot)$ & بازخور دمحور & \multirow{3}{*}{ ابتدايى } \\
\hline$d f=r$ & $q / r \cdot \pm \cdot / F V$ & $\Lambda / 91 \pm \cdot / \Delta \Delta$ & $\| / \& V \pm \cdot / \Delta q$ & $\forall \notin(\xi \Delta / V)$ & تصويرى & \\
\hline$P<\cdot 1 \cdot \cdot 1$ & $|r / T \cdot \pm \cdot| q r$ & $\mid r / \Delta \cdot \pm \cdot / V \Delta$ & $\mid r / F T \pm \cdot / V D$ & TG $(r V / I)$ & كنترل & \\
\hline$F=r / \Delta F$ & $\varepsilon \pm 1 / T V$ & $9 \pm 1 / \Delta \Lambda$ & II/AD \pm I/G & $V(1 \cdot)$ & بازخوردمحور & \multirow{3}{*}{ راهنمايى } \\
\hline$d f=r$ & $q / 4 F \pm 1 / r 1$ & $V / \Lambda \Lambda \pm I / 4$. & س & $9(1 / / 9)$ & تصويرى & \\
\hline$P=.1 .19$ & $1 \cdot 195 \pm \cdot 19$. & $11 / \cdot 9 \pm 1 / \cdot 0$ & $11 / r V \pm 1 / \cdot V$ & $19(Y T / 9)$ & كنترل & \\
\hline $\mathrm{F}=\Delta / \uparrow \Lambda$ & $V / 1 / \pm 1 / r$. & $9 / 9 \varphi \pm 1 / \% 4$ & $\mid r \pm V / \Delta F$ & $9(1 / / 9)$ & بازخور دمحور & \multirow{3}{*}{ متوسطه } \\
\hline$d f=r$ & $1 \cdot / r \cdot \pm 1 / V \Delta$ & $9 / 4 \cdot \pm 1 / v 9$ & $q / r \cdot \pm r / \cdot V$ & $\Delta(V / I)$ & تصويرى & \\
\hline$P=\cdot / \cdot \cdot r$ & $1 \cdot / r \Delta \pm 1 / 1 r$ & $9 / \pi \Delta \pm 1 / 19$ & $1 \cdot 1 / \pi \pm 1 / r r$ & $\mid r(\mid V / I)$ & كنترل & \\
\hline $\mathrm{F}=9 / 99$ & Q & $9 / 19 \pm 1 / 41$ & $11 \pm r / I V$ & $9(\Lambda / 9)$ & بازخوردمحور & \multirow{3}{*}{ دييلم } \\
\hline$d f=r$ & $1 \cdot / K \pm T / K F$ & $V \pm r / 99$ & $\Lambda / r r \pm r / \cdot V$ & $r(\boldsymbol{F} / \mu)$ & تصويرى & \\
\hline$P=\cdot / \cdot \cdot 1$ & $N / T V \pm I / I V$ & N/\& $\pm 1 / \% q$ & $9 / \cdot 9 \pm 1 / 9$. & $\|(\mid Q / V)$ & كنترل & \\
\hline
\end{tabular}

تبعيت دارويى در بلافاصله بعد از آموزش و نيز ششهفته بعد

بحث از آموزش مشاهده نشد.

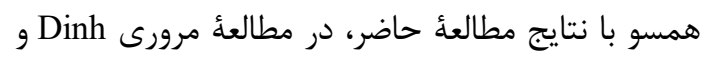
همكاران (19 • (Y) اثربخشى روش بازخوردمحور بر رفتارهاى

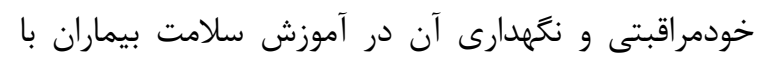

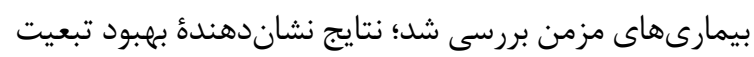

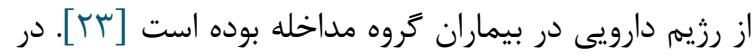

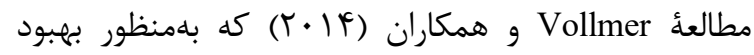
يايبندى به داروهاى بيمارىهاى قلبىعروقى باستفادهاز مداخله يادآورى تلفنى در مقايسه با مراقبت معمول انجام شده

براساس نتايج، روش بازخوردمحور و تصويرى هر دو سبب

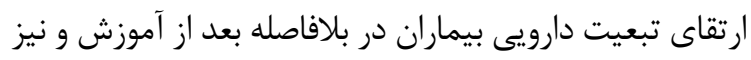
ششهفته بعد از آموزش نسبت به بدو ورود به مطالعه شدهاند. در گروه بازخوردمحور در هر مرحله نسبت به مرحله قبل ارتقا

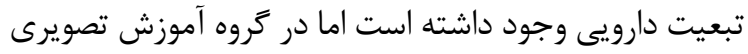

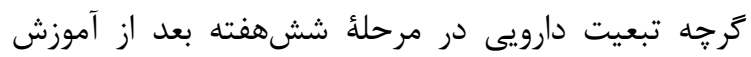
نسبت به بدو ورود افزايش يافته است ولى نسبت به بلافاصله

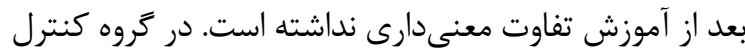

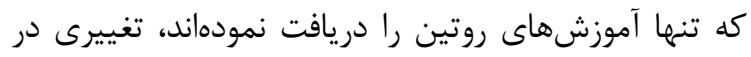


معنادارى بين اين دو روش در ششهفته بعد از آموزش وجود

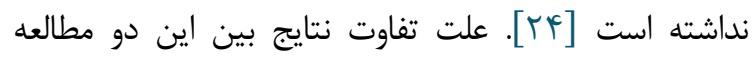

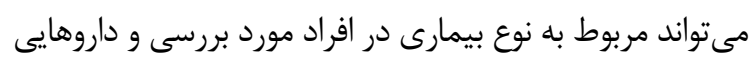

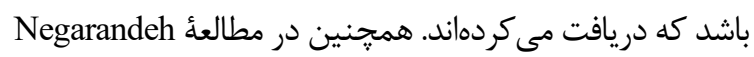

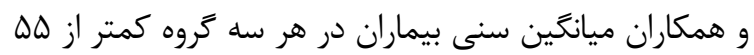

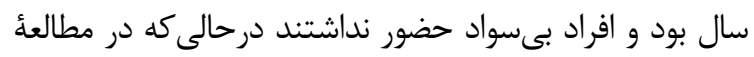

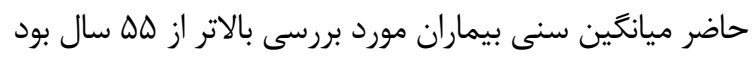

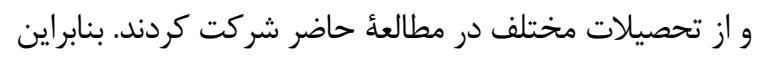

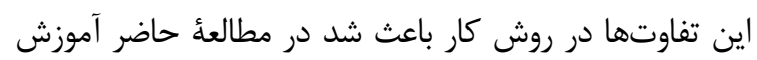

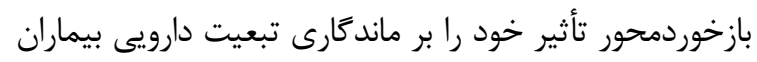
بهتر نشان دهد. نتايج مطالعأ حاضر نشان داد در افراد با سطوح مختلف

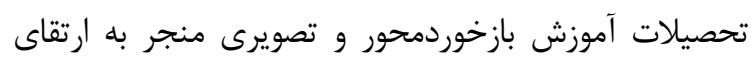

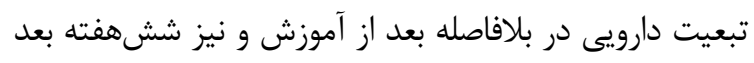

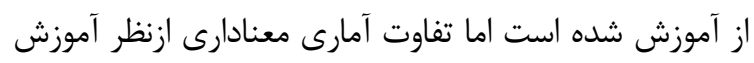

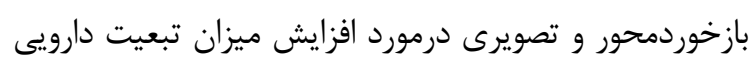

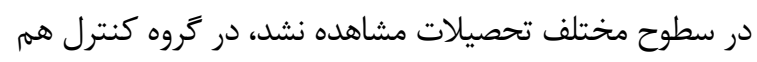
در هيج سطحى از تحصيلات، ارتقايى در تبعيت دارويى بيماران

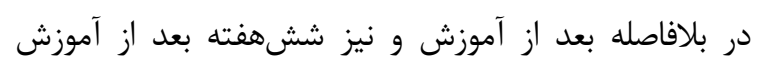

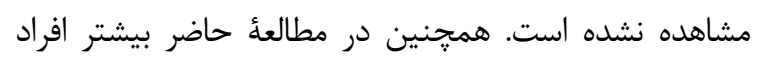

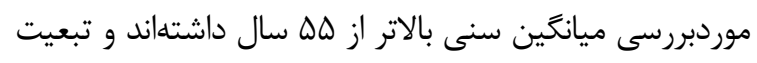
دارويى آنها در سطح يايينى قرار داشت، در اين راستا مطالعات

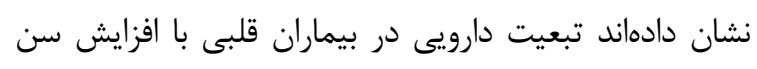

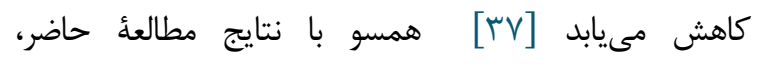
Negarandeh رسيدند هر دو روش آموزشى بازخوردمحور و و تصويرى، دانئ

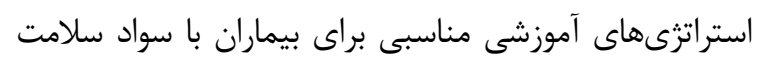

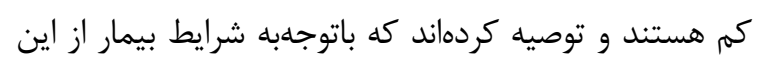

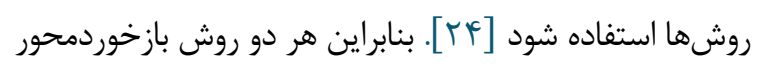

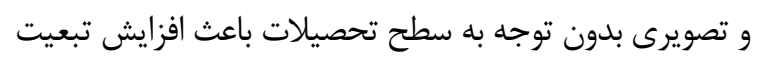

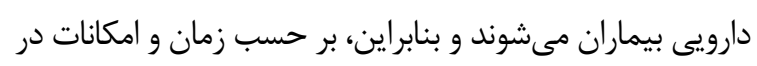

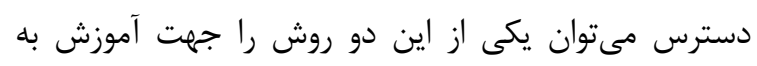

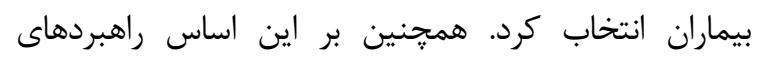

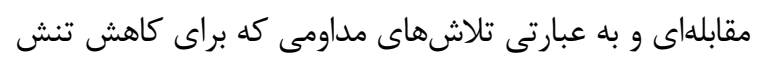

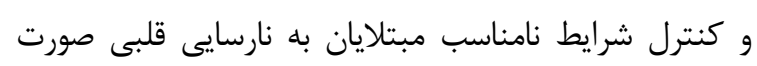

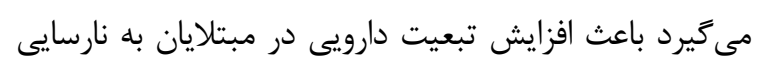

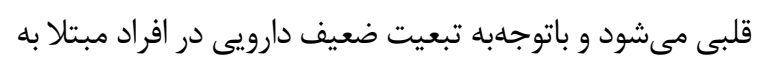

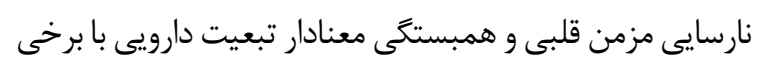

است، نتايج نشاندهندة بهبود در تبعيت دارويى كروه مداخله

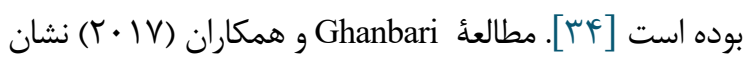

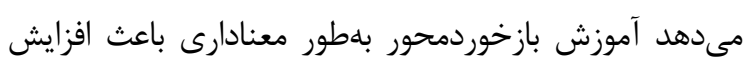

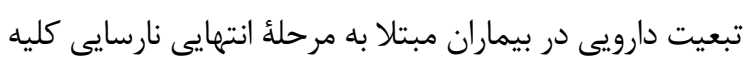

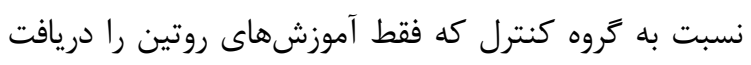

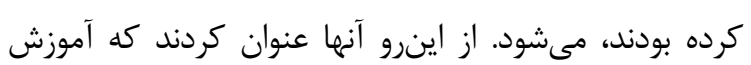

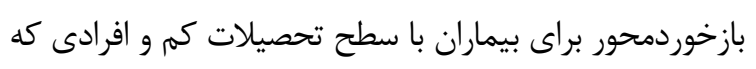

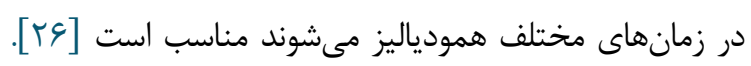

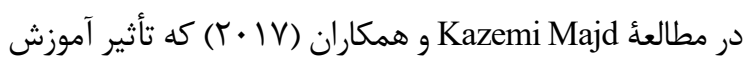

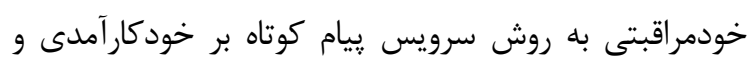

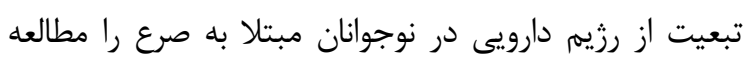

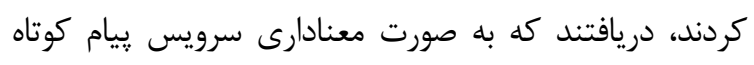

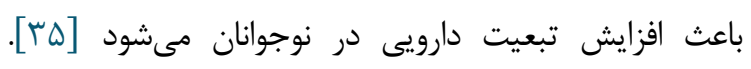

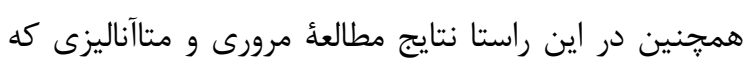

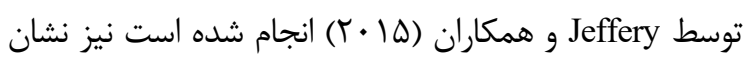

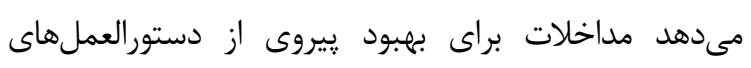

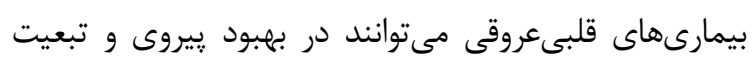

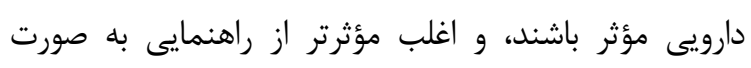

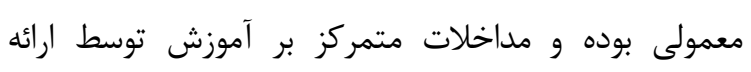

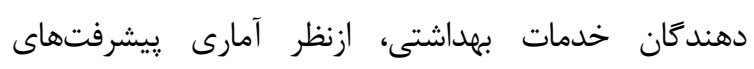
جشمخيرى را در بهبود وضعيت بيماران و تبعيت آنان نشان آنسان مىدهد [عب]. بنابراين، مىتوان دريافت كه بِيخيرى و آموزش

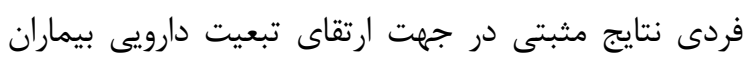

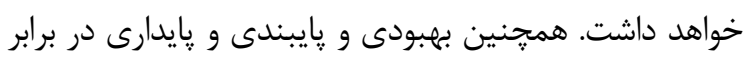

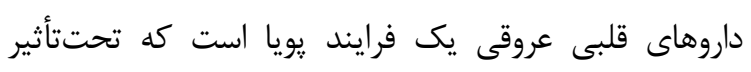

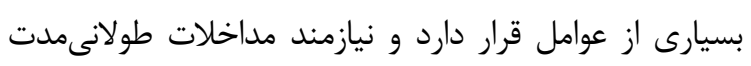
متعدد براى ترويج مصرف دارو در بيماران است. براساس نتايج مطالعه حاضر بلافاصله بعد از آموزش بـ داريه

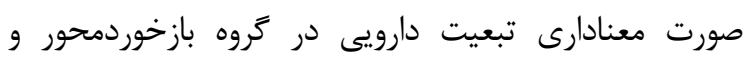

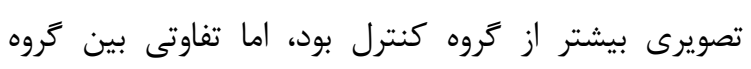

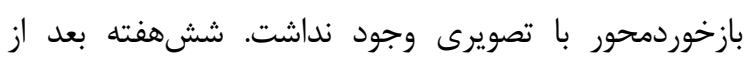

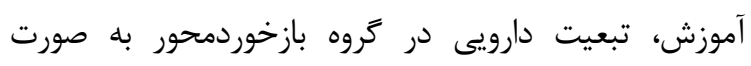

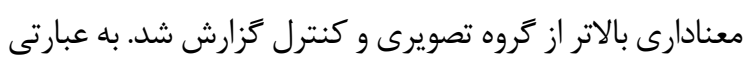

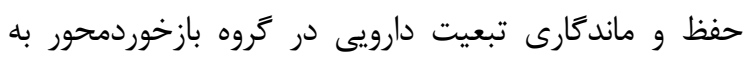

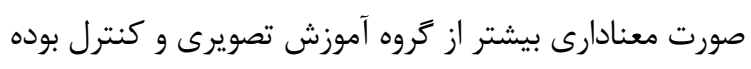

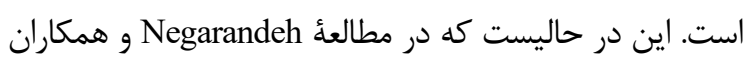

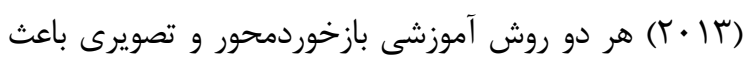

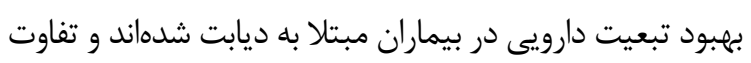


در گروه آموزشى بازخوردمحور بيشتر از گروه آموزش تصويرى

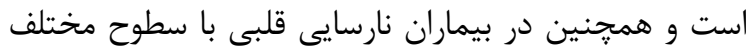

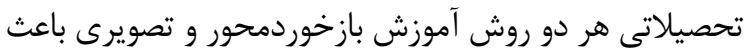

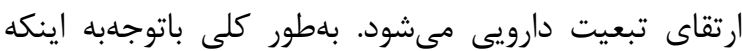
ماندگارى تبعيت دارويى در بيماران نارسايى قلبى باستفادهاز

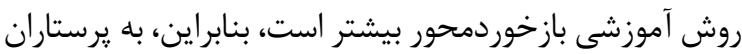

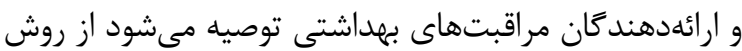
بازخوردمحور در آموزش بيماران قلبى استفاده كنند.

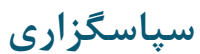

اين يزوهش در كميته اخلاق در يزوهش با شناسه IR.UMSHA.REC.1397.403 به تصويب رسيده است. يروهشكَان از معاونت يزوهشى دانشخاه علوم يزشكى همدان جهت حمايت مالى و از همةٔ مسئولين و يرستاران بخش هاى ئى بيمارستان قلب فرشجيان همدان كه ما را در انجام اين تحقيق يارى نمودند تشكر مى كنند.

تعارض در منافع

بين نويسند

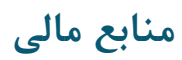

منابع مالى اين مطالعه توسط نويسندكان تامين شده است.

\section{References}

1. WHO. Cardiovascular diseases Geneva: World Health Organization; 2019 [Available from: https://www.who.int/health-topics/cardiovasculardiseases\#tab=tab 1 .

2. Fihn SD, Blankenship JC, Alexander KP, Bittl JA, Byrne JG, Fletcher BJ, et al. 2014 ACC/AHA/AATS/PCNA/SCAI/STS focused update of the guideline for the diagnosis and management of patients with stable ischemic heart disease: A report of the American College of Cardiology/American Heart Association Task Force on Practice Guidelines, and the American Association for Thoracic Surgery, Preventive Cardiovascular Nurses Association, Society for Cardiovascular Angiography and Interventions, and Society of Thoracic Surgeons. Journal of Thoracic and Cardiovascular Surgery. 2015;149(3):e5-e23.

3. DiMatteo MR, Giordani PJ, Lepper HS, Croghan TW. Patient adherence and medical treatment outcomes a meta-analysis. Medical care. 2002:794-811. [DOI:10.1097/00005650-200209000-00009] [PMID]
از راهبردهاى مقابلهاى، ارائه برنامههاى آموزشى-مشاورهاى كه يكى از راهبردهاى مقابلهاى هستند، در اين بيماران ضرورى به

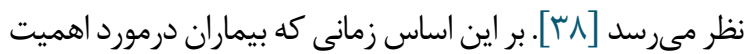
داروها، اثر درمانى، عوارض احتمالى و ساير موارد مرتبط با داروها اطلاعات كسب مى كنند، يذيرش بيشتر براى مصرف داروها دارند. از محدوديتهاى اين مطالعه تكميل : يرسشنامهها

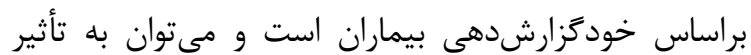

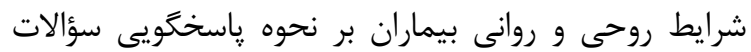
يرسشنامه و نتايج اشاره كرد، كه اين موضوع از كنترل محقق

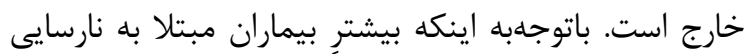
قلبى به مدت طولانى بايد دارو مصرف كنند بنابراين، تكرار آموزش براى اين بيماران مىتواند بسيار كمك كننده باشد.

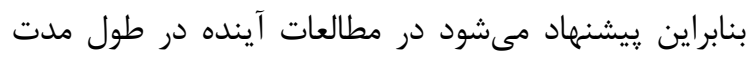

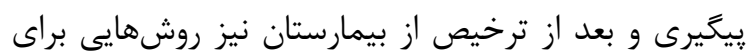

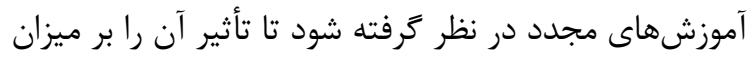
تبعيت دارويى بيماران مبتلا به نارسايى قلبى را مشاهده و نتايج را با مطالعات حاضر مقايسه كنيم.

$$
\text { نتيجه گيرى }
$$

هر دو روش آموزش بازخوردمحور و تصويرى باعث افزايش تبعيت دارويى در بيماران مبتلا به نارسايى قلبى مى شودود اما

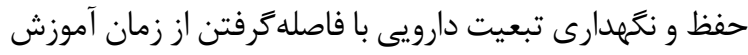

4. Lawrence D, Miller JH, Flexner CW. Medication Adherence. The Journal of Clinical Pharmacology. 2017;57(4):422-7. [DOI:10.1002/jcph.862] [PMID]

5. Naderi SH, Bestwick JP, Wald DS. Adherence to drugs that prevent cardiovascular disease: meta-analysis on 376,162 patients. The American journal of medicine. 2012;125(9):882-7.

[DOI:10.1016/j.amjmed.2011.12.013] [PMID]

6. Zhang Y, Wu S-H, Fendrick AM, Baicker K. Variation in medication adherence in heart failure. JAMA internal medicine. 2013;173(6):468-70. [DOI:10.1001/jamainternmed.2013.2509] [ [PMCID]

7. Kharameh ZT, Khoshravesh S, Noori R, Abdolmalaki M, Bakhshi M. Determinants of medication adherence among Iranian elderly patients with chronic diseases. Jundishapur Journal of Chronic Disease Care. 2018;7(3). [DOI:10.5812/jjcdc.68310]

8. Seyedfatemi N, Zeinali E, Bahremand M, Mehran A, Zeinali M. The Relationship Between Medication Adherence and Coping Skills in Patients With Heart Failure. Avicenna Journal of Nursing and Midwifery 
Care.

2019;27(2):89-96.

[DOI:10.30699/sjhnmf.27.2.89]

9. Dianati M, Taghadosi M. Medication adherence rate and related factors in patients with acute coronary syndrome after discharge from Shahid Beheshti Hospital in Kashan during 2017-2018. KAUMS Journal (FEYZ). 2019;23(2):201-8.

10. Zare S, Shams M, Fararouei M, Shariatinia S. Antihypertensive Drugs Adherence in Heart Disease Patients Referring to the Imam Reza Clinic in Shiraz. Sadra Medical Sciences Journal. 2018;6(2):151-60.

11. Ataee M, Ahmadi-Jouybari T, Hosseini SN, Ahmadi E, Emdadi S, Farhadian $M$, et al. Self-care in Cardiovascular Patients: a Cross-Sectional Study in Hamadan County, the west of Iran. Journal of Biology and Today's World. 2014;3(4):68-72. [DOI:10.15412/J.JBTW.01030403]

12. Napolitano F, Napolitano P, Angelillo IF, Group CW. Medication adherence among patients with chronic conditions in Italy. The European Journal of Public Health. 2015;26(1):48-52. [DOI:10.1093/eurpub/ckv147] [PMID]

13. Bahonar A, Sarrafzadegan N, Kelishadi R, Shirani S, Ramezani MA, Taghdisi MH, et al. Association of socioeconomic profiles with cardiovascular risk factors in Iran: the Isfahan Healthy Heart Program. International journal of public health. 2011;56(1):3744. [DOI:10.1007/s00038-010-0125-8] [PMID]

14. Downey LV, Zun LS. Assessing adult health literacy in urban healthcare settings. J Natl Med Assoc. 2008;100(11):1304-8. [DOI:10.1016/S00279684(15)31509-1]

15. Panagiotakos DB, Pitsavos C, Chrysohoou C, Vlismas K, Skoumas Y, Palliou K, et al. The effect of clinical characteristics and dietary habits on the relationship between education status and 5-year incidence of cardiovascular disease: the ATTICA study. European journal of nutrition. 2008;47(5):258. [DOI:10.1007/s00394-008-0720-0] [PMID]

16. Van Riet EE, Hoes AW, Wagenaar KP, Limburg A, Landman MA, Rutten FH. Epidemiology of heart failure: the prevalence of heart failure and ventricular dysfunction in older adults over time. A systematic review. European journal of heart failure. 2016;18(3):242-52. [DOI:10.1002/ejhf.483] [PMID]

17. Yap AF, Thirumoorthy T, Kwan YH. Medication adherence in the elderly. Journal of Clinical Gerontology and Geriatrics. 2016;7(2):64-7. [DOI:10.1016/j.jcgg.2015.05.001]

18. Seyedoshohadaee M, Babaeeyan Kshtelee F, Seyyed Fatemi N, Saravi M, Haghani H. The Effect of SelfCare Education on the Resilience of the Patients With Heart Failure. JCCNC. 2018;4(3):165-72. [DOI:10.32598/jecnc.4.3.165]

19. Alligood M. Nursing Theory: Utilization and Application. 5th ed. United States: Mosby; 2014.

20. Ahmadi A, Soori H, Mehrabi Y, Etemad K, Samavat $\mathrm{T}$, Khaledifar A. Incidence of acute myocardial infarction in Islamic Republic of Iran: a study using national registry data in 2012. Eastern Mediterranean

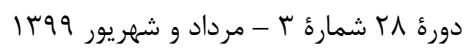

health journal. 2015;21(1):5-12.
[DOI:10.26719/2015.21.1.5] [ [PMID]

21. Javadzade SH, Sharifirad G, Radjati F, Mostafavi F, Reisi M, Hasanzade A. Relationship between health literacy, health status, and healthy behaviors among older adults in Isfahan, Iran. Journal of education and health promotion. 2012;1. [DOI:10.4103/22779531.100160] [PMID] [PMCID]

22. McCormack L, Thomas V, Lewis MA, Rudd R. Improving low health literacy and patient engagement: A social ecological approach. Patient Educ Couns. 2017;100(1):8-13. [DOI:10.1016/j.pec.2016.07.007] [PMID]

23. Dinh TTH, Bonner A, Clark R, Ramsbotham J, Hines S. The effectiveness of the teach-back method on adherence and self-management in health education for people with chronic disease: a systematic review. JBI Database System Rev Implement Rep. 2016;14(1):210-47. [DOI:10.11124/jbisrir-20162296] [PMID]

24. Negarandeh R, Mahmoodi H, Noktehdan H, Heshmat $\mathrm{R}$, Shakibazadeh E. Teach back and pictorial image educational strategies on knowledge about diabetes and medication/dietary adherence among low health literate patients with type 2 diabetes. Prim Care Diabetes. 2013;7(2):111-8. [DOI:10.1016/j.pcd.2012.11.001] [PMID]

25. Dinh TTH, Clark R, Bonner A, Hines S. The effectiveness of health education using the teach-back method on adherence and self-management in chronic disease: a systematic review protocol. JBI Database System Rev Implement Rep. 2013;11(10):30-41. [DOI:10.11124/jbisrir-2013-900]

26. Ghanbari A, Nourozi Tabrizi K, Dalvandi A, Kavari $\mathrm{SH}$, Noroozi M. Effect of an educational program based on the teach-back method on adherence to treatment regimen in dialysis patients with end stage renal disease referred to Sina Hospital during 20152016. Iranian Journal of Rehabilitation Research in Nursing. 2017;4(1):24-30.

27. Oliveira-Filho AD, Barreto-Filho JA, Neves SJF, Lyra Junior DPd. Association between the 8-item Morisky Medication Adherence Scale (MMAS-8) and blood pressure control. Arquivos brasileiros de cardiologia. 2012;99(1):649-58. [DOI:10.1590/S0066782X2012005000053] [PMID]

28. Mehrtak M, Hemmati A, Bakhshzadeh A. Health Literacy and its Relationship with the medical, dietary Adherence and exercise in Patients with Type II Diabetes mellitus. Journal of Health Literacy. 2018;3(2):137-44.

29. Awuah-Asamoah M. Effects of Teach-Back Method of Education on Knowledge of Heart Failure Self-Care Management and Post-Discharge Knowledge Retention: George Washington University; 2019.

30. Boyde M, Peters R, New N, Hwang R, Ha T, Korczyk D. Self-care educational intervention to reduce hospitalisations in heart failure: a randomised controlled trial. European Journal of Cardiovascular Nursing. 2018;17(2):178-85 [DOI:10.1177/1474515117727740] [PMID]

$$
\text { مجله مراقبت يرستارى و مامايى ابنسينا }
$$


31. Dinh H, Bonner A, Ramsbotham J, Clark R. Selfmanagement intervention using teach-back for people with heart failure in Vietnam: A cluster randomized controlled trial protocol. Nursing \& health sciences. 2018;20(4):458-63. [DOI:10.1111/nhs.12534] [PMID]

32. Riegel B, Moser DK, Buck HG, Dickson VV, Dunbar $\mathrm{SB}$, Lee CS, et al. Self-care for the prevention and management of cardiovascular disease and stroke: A scientific statement for healthcare professionals from the American Heart Association. Journal of the American Heart Association. 2017;6(9):e006997. [DOI:10.1161/JAHA.117.006997] [PMID] [PMCID]

33. Khajavi A, Moeini M, Shafiei D. The Impact of a WebBased Family-Oriented Supportive Education Program in Adher-ence to Treatment of The Heart Failure Patients After Discharge From Hospital; A Randomized Clinical Trial. Journal of Clinical Nursing and Midwifery. 2018;7(3):286-95.

34. Vollmer WM, Owen-Smith AA, Tom JO, Laws R, Ditmer DG, Smith DH, et al. Improving adherence to cardiovascular disease medications with information technology. The American journal of managed care. 2014;20(11 Spec No 17):SP502.

35. Kazemi Majd R, Hosseini M, Safi MH, Norouzi K, Hoseinzadeh S. The Effect of Self-care Education Based on Short Message Service on Self-efficacy and Adherence to the Medication Regimen in Adolescents with Epilepsy Referred to Iran Epilepsy Association of in 2016. Journal of Nursing Education (JNE). 2017;6(4).

36. Jeffery RA, To MJ, Hayduk-Costa G, Cameron A, Taylor C, Van Zoost C, et al. Interventions to improve adherence to cardiovascular disease guidelines: a systematic review. BMC family practice. 2015;16(1):147. [DOI:10.1186/s12875-015-0341-7] [PMID] [PMCID]

37. Shariatinia S. Antihypertensive Drugs Adherence in Heart Disease Patients Referring to the Imam Reza Clinic in Shiraz. 2018.

38. Zeinali e, zeinali $\mathrm{m}$, bahremand $\mathrm{m}$. The Association Between Medication Adherence and Coping Sterategies in Chronic Heart Failure Patients. Avicenna Journal of Nursing and Midwifery Care. 2019;27(2). [DOI:10.30699/sjhnmf.27.2.89] 